\title{
Fabrication and Characterization of Glucose Fuel Cells with a Microchannel Fabricated on Flexible Polyimide Film
}

\author{
Yudai Fukushi ${ }^{\text {, }}$ Syohei Koide ${ }^{a}$, Ryuta Ikoma ${ }^{a}$, Wataru Akatsuka ${ }^{\text {, }}$ \\ Seiya Tsujimurac ${ }^{c}$ and Yasushiro Nishioka ${ }^{a}$ \\ ${ }^{a}$ Department of Precision Machinery Engineering, College of Science and Technology, Nihon University, \\ 7-24-1 Narashinodai, Funabashi, Chiba 274-8501, Japan \\ ${ }^{b}$ College of Engineering Sciences, University of Tsukuba, 1-1-1 Tennodai, Tsukuba, Ibaraki 305-8573, Japan \\ ${ }^{c}$ Division of Materials Science, Faculty of Pure and Applied Sciences, University of Tsukuba, \\ 1-1-1 Tennodai, Tsukuba, Ibaraki 305-5358, Japan \\ nishioka@eme.cst.nihon-u.ac.jp
}

\begin{abstract}
In this work, a glucose fuel cell was fabricated using microfabrication processes assigned for microelectromechanical systems. The fuel cell was equipped with a microchannel to flow an aqueous solution of glucose. The cell was fabricated on a flexible polyimide substrate, and its porous carbon-coated aluminum $(\mathrm{Al})$ electrodes of $2.8 \mathrm{~mm}$ in width and $11 \mathrm{~mm}$ in length were formed using photolithography and screen printing techniques. Porous carbon was deposited by screen printing of carbon black ink on the Al electrode surfaces in order to increase the effective electrode surface area and to absorb more enzymes on the electrode surfaces. The microchannel with a depth of $200 \mu \mathrm{m}$ was fabricated using a hot embossing technique. A maximum power of $0.45 \mu \mathrm{W}$ at $0.5 \mathrm{~V}$ that corresponds to a power density of $1.45 \mu \mathrm{W} / \mathrm{cm}^{2}$ was realized by introducing a $200 \mathrm{mM}$ concentrated glucose solution at room temperature.
\end{abstract}

Keyword: Flexible Glucose fuel cells, MEMS microfabrication, Biomedical technology

\section{Introduction}

Microelectromechanical systems (MEMS) have been extensively studied in recent years for biomedical applications such as diagnosis, treatment via targeted drug delivery [1] and embedded systems [2]. Amongst these, enzymatic biofuel cells that use glucose in a human body to produce electricity for embedded microsystems have been of special interest [3]. This is because they work under mild conditions of room temperature, neutral $\mathrm{pH}$ and atmospheric pressure, which make them amenable to the human body [4-19]. MEMS technologies are advantageous for biofuel cells as they enable miniaturization and mass production. Tago et al. have reported such a biofuel cell with microchannels and enzymes-modified platinum electrodes fabricated on a glass substrate [4]. However, when this device was used in vivo and subcutaneously, the fragile and inflexible glass substrate caused problems with biocompatibility. In comparison, polyimide (PI) as a substrate material offers good biocompatibility, high thermal stability, and flexibility. However, to transfer microstructures onto PI is not very easy. Nevertheless, recent reports on thermal nanoimprint techniques have shown to accurately transfer micropatterns onto PI substrates [20,21].

In this study, we report the fabrication and characterization of glucose fuel cells with a microchannel fabricated on a PI substrate using a thermal nanoimprint technique. The fuel cell investigated here was composed of a bilirubin oxidase (BOD)-adsorbed cathode and a glucose oxidase (GOD) and osmium complex-adsorbed anode $[8,9]$. The possible power generation mechanism of this cell is described in Fig. 1. GOD immobilized on the anode oxidizes glucose

\begin{tabular}{llr}
\hline Received & April & 2,2013 \\
Accepted & May & 10,2013
\end{tabular}


molecules, as a result electrons and protons are produced. The electrons are transferred to the anode through an osmium complex mediator. Then they are conducted from the anode to the cathode via an external circuit generating electricity. Oxygen $\left(\mathrm{O}_{2}\right)$ in the fuel solution is reduced by BOD immobilized on the cathode to water on reaction with electrons and protons.

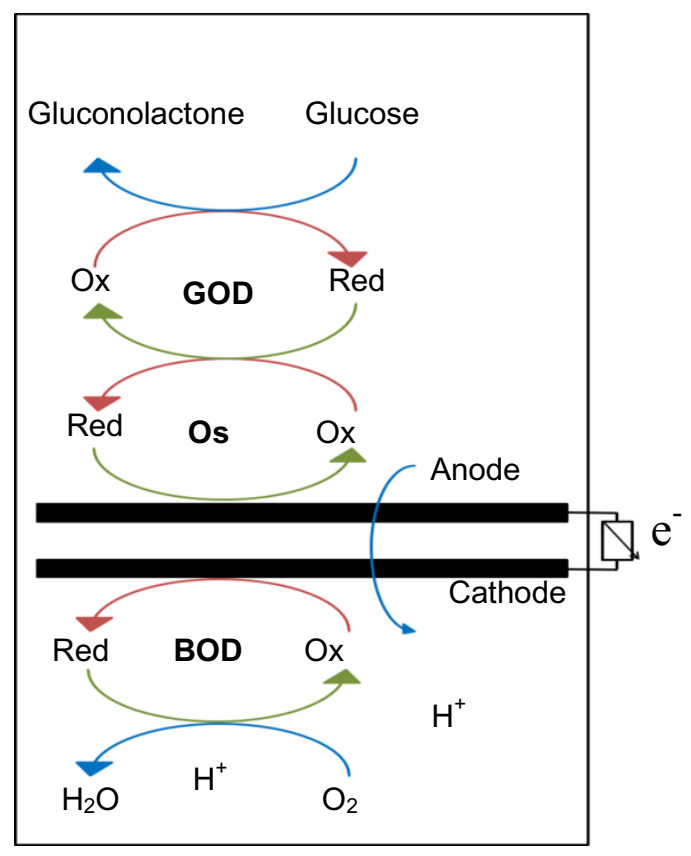

Fig. 1. Possible mechanism of power generation.

\section{Experimental}

2.1. Design of glucose fuel cells with a microchannel.

Fig. 2 shows the layout of the cathode and anode. The anode has a width of $2.8 \mathrm{~mm}$ and a length of $1 \mathrm{~mm}$, and the cathode has a width of 2.8 $\mathrm{mm}$ and length of $10 \mathrm{~mm}$. These electrodes were fabricated by photolithography on a PI sheet, coated with aluminum (Al) and then modified by carbon black and respective enzymes. The gap between the anode and cathode was $0.5 \mathrm{~mm}$. The microchannel was fabricated on another PI sheet, and it was designed to have a width of $3 \mathrm{~mm}$, a depth of $200 \mu \mathrm{m}$, and a length of $11.5 \mathrm{~mm}$. These two patterned PI substrates were stacked to form a fuel cell as shown in Fig. 3. The cathode was designed to be larger than the anode to account for the lower concentration of oxygen in comparison to that of glucose; to reduce the flux of oxygen in the upstream to the anode and consequently to improve the glucose oxidation performance [4].

In order to investigate the characteristics of the anode and cathode independently using cyclic voltammetry, one of the electrode areas was fabricated to be a silver|silver chloride $(\mathrm{Ag} \mid \mathrm{AgCl})$ reference electrode by coating the $\mathrm{Al}$ surface with an ink of $\mathrm{Ag} \mid \mathrm{AgCl}$ (BAS Inc.).

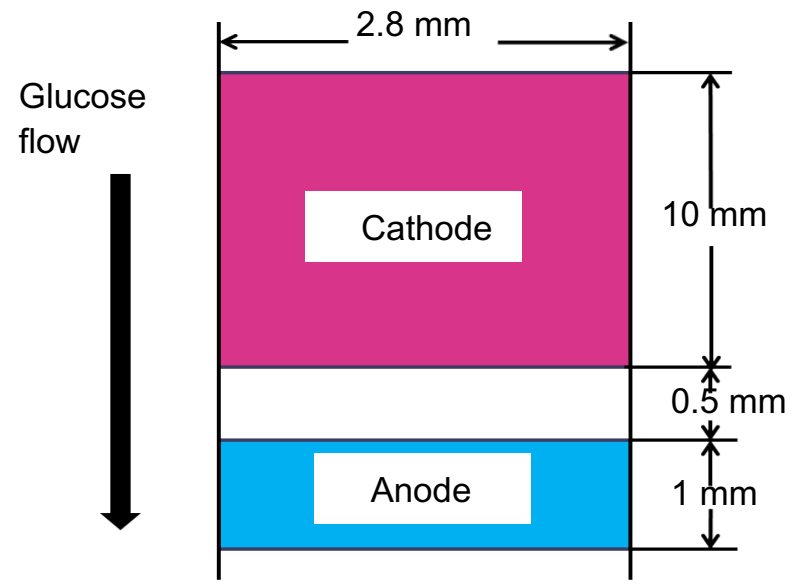

Fig. 2. Layout of the electrodes on PI substrate.

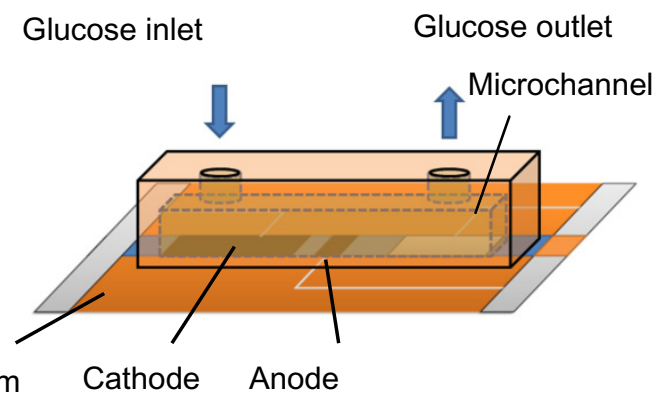

Fig. 3. Design of glucose fuel cell with a microchannel.

2.2 Fabrication processes of carbon-modified electrodes

In order to increase the amount of enzymes adsorbed on the electrode surfaces, the effective surface area was increased by coating the electrode surfaces with a carbon black ink. The carbon-modified electrodes were fabricated on a PI sheet using conventional MEMS fabrication processes as schematically described in Fig. 4. (a) First, a layer of Al was deposited on the surface of a PI sheet by thermal vacuum deposition. (b) Then, the photoresist (PR, S1830 positive) was spin coated on the Al film. (c) The electrode pattern was optically defined by photolithography. (d) The Al film was partially removed by wet chemical etching using a solution mixture (Dihydrogen phosphate $\left(\mathrm{H}_{2} \mathrm{PO}_{3}\right)$ : nitric acid $\left(\mathrm{HNO}_{3}\right)$ : acetic acid $\left.\left(\mathrm{CH}_{3} \mathrm{COOH}\right): \mathrm{H}_{2} \mathrm{O}=2: 1: 1: 1\right)$. (e) The photoresist was removed with acetone. After this, carbon-modified electrodes were formed on the surfaces of $\mathrm{Al}$ film by screen printing with a 
carbon paste (MRX-713J-A, TAMURA Corporation), which was then cured at $150{ }^{\circ} \mathrm{C}$ for 15 min. (f) Finally, the surface of the carbon paste film was coated by screen printing with an ink mixture of Ketjenblack EC 300J (KB, Lion Inc.), and polyvinylidene fluoride (PVDF, KUREHA Inc), which was subsequently cured at $80^{\circ} \mathrm{C}$ for 1 h. Fig. 5 shows a scanning electron microscope (SEM) image of the carbon-coated Al electrode surface. Porous structures were clearly observed, which suggest an increase in the effective electrode area.

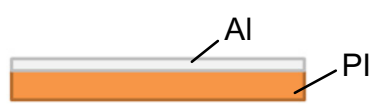

(a)

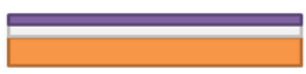

(b)

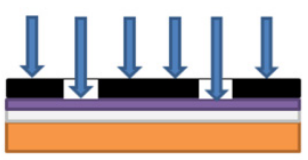

(c)

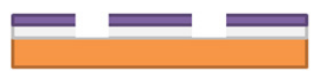

(d)

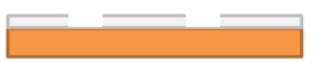

(e)

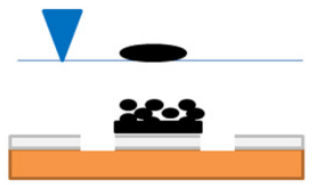

(f)
Fig. 4. Fabrication process of carbon-modified electrodes: (a) Al deposition on PI, (b) photoresist spin-coating, (c) exposure, (d) Al wet etching, (e) photoresist removal, and (f) screen printing with carbon paste.

\subsection{Fabrication process of enzyme-modified} electrodes

$1 \mathrm{mg}$ of GOD was mixed with $25 \mu \mathrm{l}$ of phosphate buffer solution (PBS, $50 \mathrm{mM}, \mathrm{pH} \mathrm{7.0)}$. Then, $6 \mathrm{mg}$ of the osmium complex mediator (Polyvinylimidazole -Os(2,2'-bipyridine)2Cl) was mixed with $25 \mu \mathrm{l}$ of PBS. Finally, $2 \mu \mathrm{l}$ of the resulting solutions was dropped on the anode (surface area of $2.8 \mathrm{~mm}^{2}$ ), and left to dry for 20 min. Similarly, $1 \mathrm{mg}$ of BOD was mixed with 25 $\mu 1$ of PBS. $2 \mu \mathrm{l}$ of the resulting solution was dropped on the cathode (surface area of $28 \mathrm{~mm}^{2}$ ) and left to dry for $20 \mathrm{~min}$.

\subsection{Fabrication process of the microchannel}

The fabrication processes of the microfluidic channel are shown in Fig. 6. (a) First, a photoresist (PR, S1830 positive) was spin coated on a silicon substrate. (b) Then, the microfluidic structure was

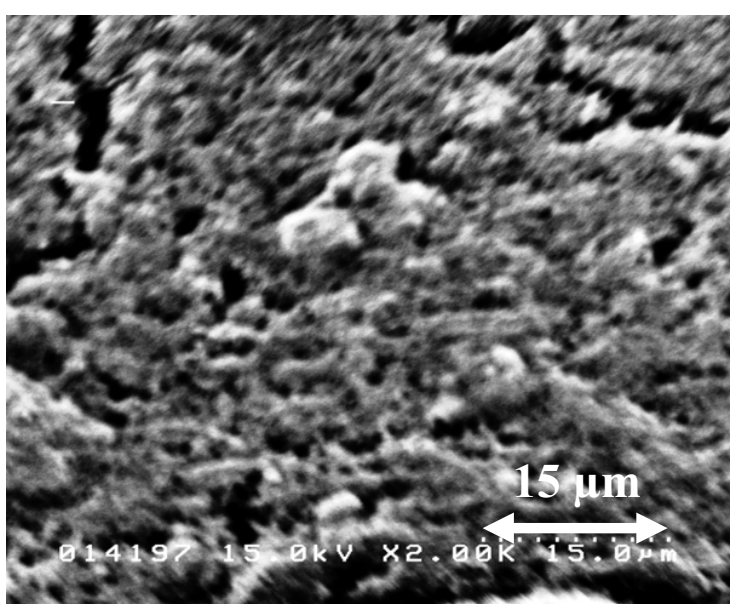

Fig. 5. SEM image of porous carbon-coated $\mathrm{Al}$ electrode.

optically defined by photolithography. (c) The silicon substrate was etched anisotropically using the Bosch process in an inductively coupled plasma (ICP) etcher (MUC21, Sumitomo Precision Products Co. Ltd.). The depth of etching was adjusted to $200 \mu \mathrm{m}$. Once the photoresist was removed, the Si mold was considered fabricated. (d) After this, the fabrication of the microchannel was performed using hot embossing as described previously $[20,21]$. First, the Si mold surface was coated with an anti-adhesion agent (OPTOOL, HD-1100TH). Then for hot embossing, the mold and a $360 \mu \mathrm{m}$ thick PI sheet (Kapton JP, DuPont) were heated to $300{ }^{\circ} \mathrm{C}$, and pressed at a constant pressure of $2 \mathrm{MPa}$ and a temperature of $300^{\circ} \mathrm{C}$ for 300 s. An embossing temperature of $300{ }^{\circ} \mathrm{C}$ was chosen because the glass transition temperature $T_{g}$ of PI was reported to be $275^{\circ} \mathrm{C}$ [20]. After cooling down to room temperature, the PI film was released from the mold. In most cases, the adhesion between the mold and the PI substrate was very strong, and fractures in the Si mold were frequently observed. (e) Finally, the PI sheet with the microchannel was stacked with the PI sheet having the carbon-coated anode and cathode, and they were fixed using acrylic plates.

\subsection{Measurements}

Electrochemical measurements were performed in a $200 \mathrm{mM}$ solution of glucose at room temperature. The electrochemical properties of the electrodes were characterized using a potentiostat (Electrochemical Analyzer, HA-1518, Hokuto Denko) having a three electrodes system, wherein the enzyme-modified electrode was the working 


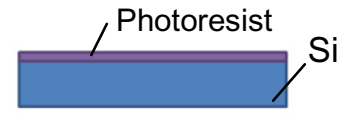

(a)

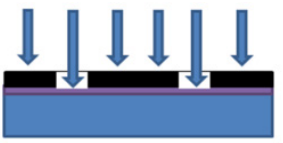

(b)

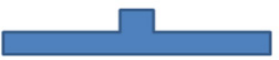

(c)

Fig. 6. Fabrication process of the fuel cell: (a) photoresist spin-coating, (b) exposure, (c) Si ICP etching, (d) hot-embossing, (e) stacking electrodes with microchannel.

electrode, the $\mathrm{Ag} \mid \mathrm{AgCl}$ modified electrode was the reference and platinum was the counter electrode.

The power measurement system used to test the fuel cell is schematically shown in Fig. 7. The glucose solution was introduced into the reaction chamber through the microchannel by pulling a syringe pump.

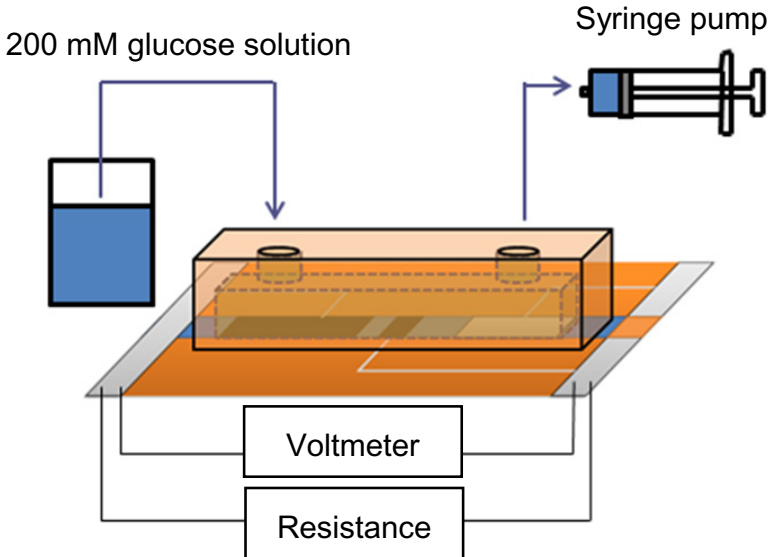

Fig. 7. Power measurement system for fuel cell.

The power generated was evaluated by measuring the cell voltage while varying the external load resistance between 0 and $3 \mathrm{M} \Omega$ The following equation was used:

$$
W=V^{2} / R \quad \text { Eq. (1), }
$$

where $R$ is the load resistance, and $V$ is the generated voltage measured between the terminals of the fuel cell. The power density was calculated by dividing $W$ with the total area of the anode and the cathode, which was $30.8 \mathrm{~mm}^{2}$.

\section{Results and discussion}

Fig. 8 shows the cyclic voltammogram of the GOD/osmium complex-modified anode in 200 $\mathrm{mM}$ glucose solution. The catalytic oxidation of glucose can be clearly seen at potentials higher than $0.12 \mathrm{~V}$. The maximum current density was $1457 \mu \mathrm{A} / \mathrm{cm}^{2}$. This superior performance was due to the promotion of oxidation reactions by GOD and fast electron transfer by the mediator osmium complex [23,24]. The high current density saturated at a potential about $0.2 \mathrm{~V}$ and then showed a decrease from about $0.3 \mathrm{~V}$. In this experiment, it is presumed that the reduction of the current density was due to the removal of the GOD/osmium complex mediator from the anode and the exhaustion of glucose near the surface of anode. Better immobilization of the enzymes to the electrode surface will help prevent their exfoliation.

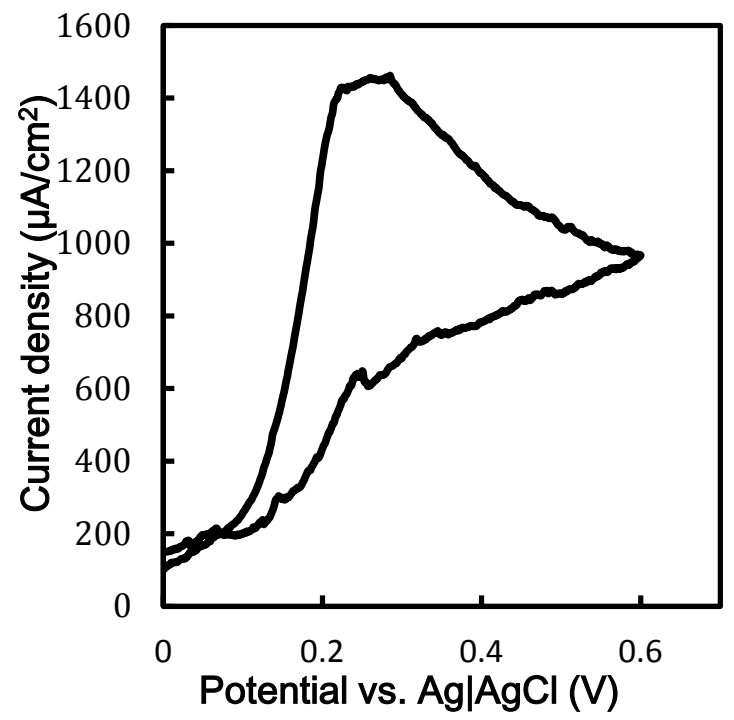

Fig. 8. Cyclic voltammogram of the GOD/ osmium complex -modified anode in $200 \mathrm{mM}$ glucose solution.

The cyclic voltammogram of the BOD-modified cathode in $200 \mathrm{mM}$ glucose solution is shown in Fig. 9. The starting potential of the $\mathrm{O}_{2}$ reduction current was about $0.5 \mathrm{~V}$. The minimum current density was $-2.91 \mu \mathrm{A} / \mathrm{cm}^{2}$. This value was almost three orders of magnitude lower than that of the anode. The stirring of fuel and bubbling of oxygen, have resulted in a high current density as reported before [6, 22, 25-28]. In this study, a high current density on reduction was not realized because the oxygen concentration in the fuel was probably low. Alternatively, perhaps the carbon ink did not increase the 
effective electrode surface area of the cathode. A low resistive Al film was used as the current collector for the glucose biofuel cells in this study to achieve a low cost of fabrication. However, it is possible that during the operation of the fuel cell, the $\mathrm{Al}$ electrodes might have eroded on interaction with the glucose solution. Al is considered to have a high ionization tendency for electrochemical corrosion. It may be necessary to use noble metals such as platinum $(\mathrm{Pt})$ or gold $(\mathrm{Au})$, which have low ionization tendency to keep the fuel cell performance from degrading. In this study, since we used $\mathrm{Al}$ as a current collector, it was presumed that the $\mathrm{Al}$ electrode was completely covered with the carbon ink.

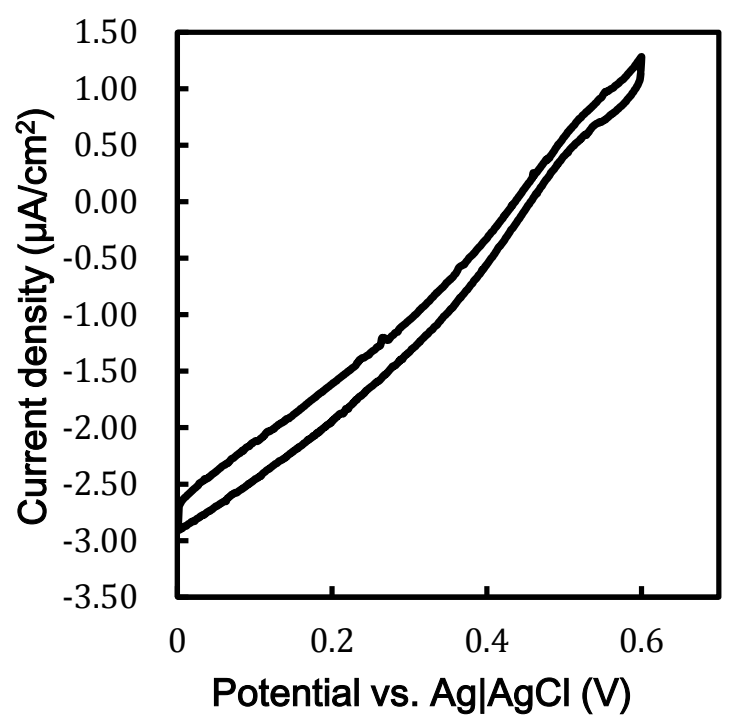

Fig. 9. Cyclic voltammogram of the BOD-modified cathode in $200 \mathrm{mM}$ glucose solution.

The relationship between the current and voltage of the fuel cell during operation is shown in Fig. 10. While the dependence of the power density on output voltage is shown in Fig. 11. The maximum power density was $1.45 \mu \mathrm{W} / \mathrm{cm}^{2}$ at 0.5 $\mathrm{V}$ when the $200 \mathrm{mM}$ glucose solution was introduced into cell by syringe pump. This maximum power density is lower by twenty factors when compared to the previously reported results [4]. This could be attributed to the extremely low current density at the cathode. In addition, the power measurements were made at room temperature, which could be another reason for the low value of the power generated in this study. Togo et al. have reported that the temperature of their fuel was maintained at $37{ }^{\circ} \mathrm{C}$ during power generation [4], which might have increased the catalytic activity of the enzymes.

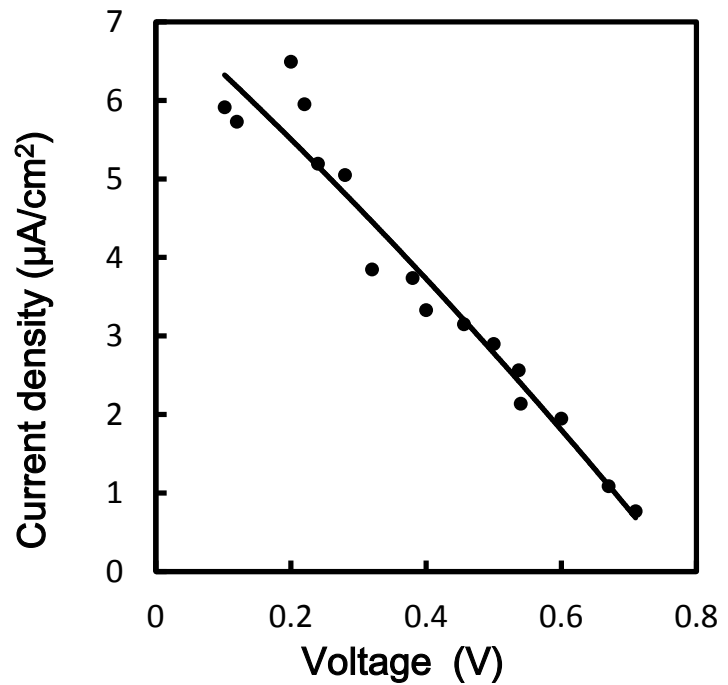

Fig. 10. Current-voltage relationship during fuel cell operation.

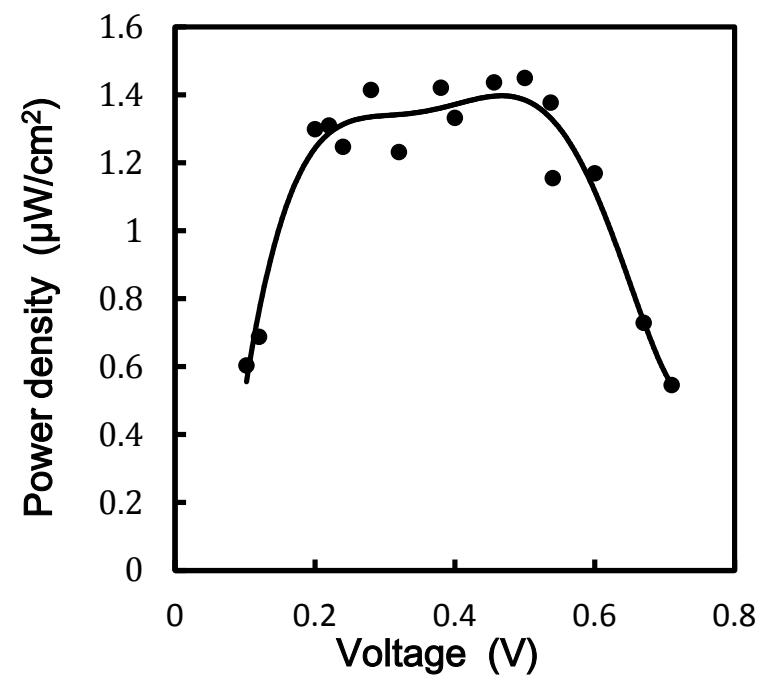

Fig. 11. The dependence of power density on the output voltage.

\section{Conclusion}

A glucose fuel cell was fabricated on a flexible PI substrate using MEMS microfabrication processes. The fuel cell had a microchannel to introduce an aqueous glucose solution. Al electrodes of width $2.8 \mathrm{~mm}$ and length $11 \mathrm{~mm}$ were formed on the PI substrate using photolithography and screen printing. Porous carbon was deposited by screen printing of carbon black ink on the $\mathrm{Al}$ electrode surfaces in order to increase the effective electrode surface area and to absorb more enzymes. The microchannel with a depth of $200 \mu \mathrm{m}$ was fabricated using a hot 
embossing technique. A maximum power of 0.45 $\mu \mathrm{W}$ at $0.5 \mathrm{~V}$ that corresponds with the power density of $1.45 \mu \mathrm{W} / \mathrm{cm}^{2}$ was realized by introducing a $200 \mathrm{mM}$ concentrated glucose solution at room temperature.

\section{Acknowledgments}

This research was conducted in supports of the staffs in the Micro Functional Device Research Center of the College of Science and Technology, Nihon University.

\section{References}

[1] N. Tsai, C. Sue, Sensors and Actuators. A 134 (2007) 555-564.

[2] X. Wei, J. Liu, Front. Energy Power Eng. China, 2(1) (2008) 1-13.

[3] Y. Tokita, T. Nakagawa, H. Sakai, T. Sugiyama, R. Matsumoto, T. Hatazawa, ECS Trans. 13 ( 21) (2008) 89-97.

[4] M. Togo, A. Takamura, T. Asai, H. Kaji, M. Nishizawa, Electrochim. Acta 52 (2007) 4669-4674.

[5] K. G. Lim, G.T.R. Palmore, Biosens. Bioelectron. 22 (2007) 941-947.

[6] Y. Kamitaka, S. Tsujimura, N. Setoyama, T. Kajino, K. Kano, PCCP Phys. Chem. Chem. Phys. 9 (2007) 1793-1801.

[7] F. Sato, M. Togo, M.K. Islam, T. Matsue, J. Kosuge, N. Fukasaku, S. Kurosawa, M. Nishizawa, Electrochem. Commun. 7 (2005) 643-647.

[8] C.M. Moore, S.D. Minteer, R.S. Martin, Lab Chip 5 (2005) 218-225.

[9] A. Heller, AiChE J. 51 (2005) 1054-1066.

[10] A. Heller, PCCP Phys. Chem. Chem. Phys. 6 (2004) 209-216.

[11] S.C. Barton, J. Gallaway, P. Atanassov, Chem. Rev. 104 (2004) 4867-4886.
[12] N. Mano, F. Mao, W. Shin, T. Chen, A. Heller, Chem. Commun. (Cambridge, United Kingdom) 4 (2003) 518-519.

[13] S. Tsujimura, K. Kano, T. Ikeda, Electrochemistry 70 (2002) 940-942.

[14] N. Mano, F. Mao, A. Heller, J. Am. Chem. Soc. 124 (2002) 12962-12963.

[15] S. Tsujimura, M. Fujita, H. Tatsumi, K. Kano, T. Ikeda, PCCP Phys. Chem. Chem. Phys. 3 (2001) 1331-1335.

[16] E. Katz, A.F. Buckmann, I. Willner, J. Am. Chem. Soc. 123 (2001) 10752-10753.

[17] T. Chen, S.C. Barton, G. Binyamin, Z.Q. Gao, Y.C. Zhang, H.H. Kim, A. Heller, J. Am. Chem. Soc. 123 (2001) 8630-8631.

[18] G.T.R. Palmore, H. Bertschy, S.H. Bergens, G.M. Whitesides, J. Electroanal. Chem. 443 (1998) 155-161.

[19] T. Tamaki, T. Ito, T. Yamaguchi, J. Phys. Chem. B111 (2007) 10312-10319.

[20] S.W. Youn, T. Noguchi, M. Takahashi, R. Maeda, Microelec. Eng. 85 (2008) 918.

[21] H. Becker, U. Heim, Sens, and Actuators A Physical. 83 (2000) 130.

[22] R. Kontani, S. Tsujimura, N. Kano, Bioelectrochemistry 76 (2009) 10.

[23] T. Kuwahara, H. Ohta, M. Kondo, M. Shimomura, Bioelectrochemistry 74 (2008) 66-72.

[24] T.J. Ohara, R. Rajagopalan, A. Heller, Anal. Chem. 1003, 65 (2003) 3512-3517.

[25] S. Tsujimura, K. Kano, T. Ikeda, $J$. Electroanal. Chem. 576 (2005) 113-120.

[26] S. Tsujimura, T. Nakagawa, K. Kano, T. Ikeda, Electrochemistry 72 (2004) 437-439.

[27] Y. Kamitaka, S. Tsujimura, K. Kataoka, T. Sakurai, T. Ikeda, K. Kano, J. Electroanal. Chem. 601 (2007) 119-124.

[28] M. Tominaga, M. Otani, M. Kishikawa, I. Taniguchi, Chem. Lett. 35 (2006) 1174-1175. 